\title{
An Insight into Special Purpose Acquisition Companies Within the United States' Healthcare Sector in 2021
}

\author{
Smerkolj $\mathbf{N}^{1}$, Jeran $\mathbf{M}^{2,3, *}$
}

1. University of Ljubljana, School of Economics and Business, Slovenia

2. University of Ljubljana, Faculty of Health Sciences, Laboratory of Clinical Biophysics, Slovenia

3. University of Ljubljana, Faculty of Electrical Engineering, Laboratory of Physics, Slovenia

* Correspondence: Marko Jeran; marko.jeran@fe.uni-lj.si

Citation: Smerkolj N, Jeran M. An insight into special purpose acquisition companies within the United States' healthcare sector in 2021. Proceedings of Socratic Lectures. 2021; 6: 88-92.

https://doi.org/10.55295/PSL.2021.D. 012

Publisher's Note: UL ZF stays neutral with regard to jurisdictional claims in published maps and institutional affiliations.

\section{(c) (1)}

Copyright: (c) 2021 by the authors. Submitted for possible open access publication under the terms and conditions of the Creative Commons Attribution (CC BY) license (https://creativecommons.org/license s/by/4.0/).

\begin{abstract}
Special purpose acquisition companies (SPAC) have become an increasingly popular way for private companies to go public due to their flexibility and ease in regulatory procedures. SPAC is in essence a blank check company with no business operations and assets (apart from cash and cash equivalents after the initial public offering (IPO)) that is formed with a purpose of acquiring a certain private company or companies. SPAC's initial public offering proceeds in the United States in 2021 have surpassed those of 2020 and have just passed 160 billion dollars. Merger

activity of SPACs and target companies has been especially intense in sectors of technology and healthcare. This scientific contribution analyzes IPO proceedings and total enterprise values (TEV) data for SPACs in the healthcare sector in the US and portrays a comparison with the technology sector.
\end{abstract}

Keywords: Special purpose acquisition company, initial public offering, merger, healthcare sector 


\section{Introduction and theoretic overview}

Special purpose acquisition companies (SPAC) have become a popular and preferred vehicle for taking private companies public with 83.4 billion dollars raised in 2020 and 151.6 billion dollars raised in the first nine months of 2021 in the United States (SPAC Research Database, 2021). Sectors of technology and healthcare accounted for almost $80 \%$ of all initial public offering proceedings (IPOs) in the United States in 2020, thus it is to no surprise that $60 \%$ of completed SPAC mergers in 2020 were in information technology, healthcare and consumer discretionary sectors (The Goldman Sachs Group, Inc., 2021). European initial public offerings of SPACs are substantially lower than those overseas with only four IPOs (compared to 248 in the US) and 496 million dollars raised in 2020 (Heredia et al., 2021). European SPACs deals have shown rapid growth in 2021, however, the importance of SPACs in Europe remains lower than that in the United States.

Special purpose acquisition company is a publicly-traded blank-check company without any business activity - its main goal is to raise capital through an IPO for a future acquisition $^{1}$ of an operating private company (Hale, 2006). A so-called sponsor creates a SPAC, which is taken public by underwriters (investment banks) - during the phase of an initial public offering, a SPAC sells units made of a common share and a fraction warrant for a fixed price of 10 dollars. Important aspects of SPACs are two rights that are bound to each common share purchased by investors - the right to redeem and the right to vote. The first right allows investors to redeem their shares and gather 10 dollars for each share plus the accrued interest if they don't want to participate in the merger with a selected private company, and the second right allows investors to vote on the merger with a proposed private company (The Goldman Sachs Group Inc., 2021). Another peculiarity of SPACs is the previously mentioned warrant, which gives an investor a right to purchase a fraction of a common share at an exercise price of 11.50 dollars per share. SPAC can use the received capital from IPO only to acquire a targeted company, to contribute to the capital of a newly formed company via merger, to repay investors if SPAC doesn't complete a merger or to fulfil investors' right to redeem (Klausner et al., 2020). SPAC has two years to complete an acquisition or merger, otherwise, it has to repay the initial investment to the investors (Jenkinson et al., 2011). Once the initial public offering phase has been completed, the management team of SPAC starts searching for a target company. In many instances, the target company is not known in advance, which increases the risk associated with investment during the IPO phase. Sponsor and target company agree to a letter of intent and new investors are brought in with the so-called PIPE (private investment in public equity) phase (Klausner et al., 2020). Shareholders vote on a potential merger and if a merger is approved, SPAC becomes an operating company and will usually change its name and ticker.

Special purpose acquisition companies as a vehicle of taking private companies public aren't a new thing, they have been present since the nineties. Last year, SPACs have seen a huge surge both in the number of IPOs (a 320\% increase compared to 2019) and in total proceeds (a $513 \%$ increase compared to 2019). Analysts predict that this surge partially corresponds to the disruption caused by COVID-19. When many companies were faced with the problem of irregular cash flows, public companies had easier access to debt and equity markets (The Goldman Sachs Group Inc., 2021). Additionally, investors seeking investments in businesses with higher growth potential turned to early-stage businesses (in industries such as nanotechnology, green technology and gambling) that used SPACs as their way to the public market. Figure 1 shows the number of initial public offerings of SPACs and yearly accumulative proceedings in the United States.

\footnotetext{
${ }_{1}$ Although the name suggests the acquisition of a company it is often merely a merger of SPAC and target company. This issue and the problem of dilution of ownership is discussed and analyzed in-depth by Klausner and Ohlrogge (2020). In this article, we will take acquisition and merger as being synonymous, although there are important theoretic differences.
} 


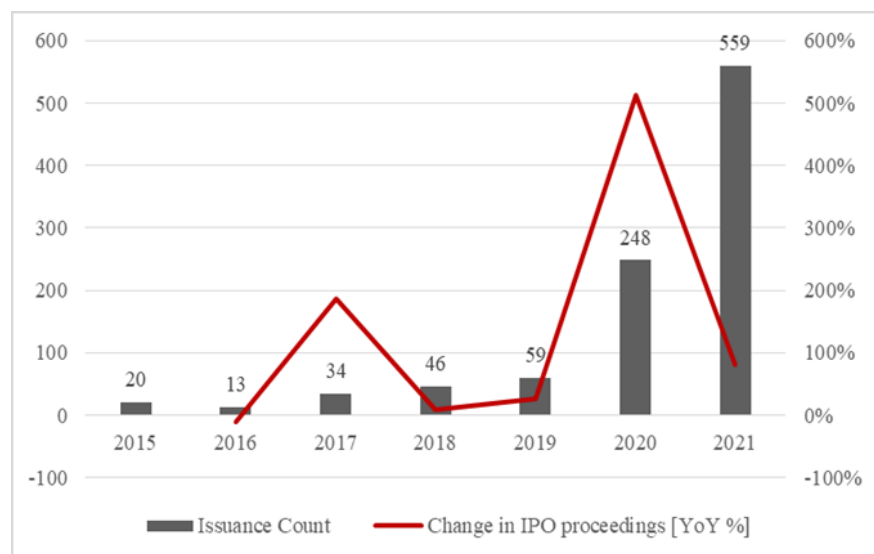

Figure 1. Special purpose acquisition companies' (SPACs) initial public offerings (IPOs) in the United States. The left vertical axis shows the total number of IPOs of SPACs in a given year (labelled issuance count), the right vertical axis shows the percentage change in IPO proceedings in billions of USD in a given year. The authors' calculation is based on historical data available at the SPAC Insider Statistics database.

\section{Methods}

Quantitative data has been gathered from publicly available databases (such as SPAC Research and SPAC Insider) that consolidate information from companies' legally binding reports and filings to the Securities and Exchange Commission (SEC). Information gathered include but are not limited to a number of SPACs' IPOs, IPO proceedings (individual and total), the value of merger transactions (individual and total) and total enterprise value after the merger (individual and total). Authors have used various tools for quantitative analysis and descriptive statistics, which can be seen in Table 1. Table and graphs were generated in a Microsoft Excel environment.

Table 1. Descriptive stastistics data on SPACs in the healthcare sector in the US (Jan-Nov 2021). The authors' calculation is based on data available at the SPAC Insider Statistics database.

\begin{tabular}{|l|l|l|l|}
\hline & $\begin{array}{l}\text { Pre-mergers; IPO proce- } \\
\text { eds }(\mathrm{M} \$)\end{array}$ & $\begin{array}{l}\text { Active mergers; total } \\
\text { enterprise value (M\$) }\end{array}$ & $\begin{array}{l}\text { Completed mergers; total } \\
\text { enterprise value (M\$) }\end{array}$ \\
\hline Mean & 208.9 & 2899.7 & 1752.5 \\
\hline Standard error & 16.8 & 1869.6 & 400.4 \\
\hline Median & 200.0 & 660.0 & 1084.5 \\
\hline Mode & 230.0 & no mode & 184.0 \\
\hline Standard deviation & 126.6 & 7708.6 & 2532.1 \\
\hline Range & 805.0 & 32472.0 & 15080.0 \\
\hline Minimum & 57.5 & 128.0 & 84.0 \\
\hline Maximum & 862.5 & 32600.0 & 15164.0 \\
\hline Count & 57 & 17 & 40 \\
\hline
\end{tabular}

\section{Results and Discussion}

As previously mentioned, $60 \%$ of completed SPAC mergers in the United States in 2020 were in sectors of information technology, healthcare and consumer discretionary. In the following paragraph, we focus on the developments of SPAC activity within the healthcare sector and present statistics on closed mergers, active merger transactions and completed initial public.

There have been 40 completed mergers in the first eleven months of 2021 in the healthcare sector with an average total enterprise value after the merger of 1.75 billion dollars and a median of 1.08 billion dollars. Total enterprise values vary from 84 million to 
15.2 billion dollars with a standard deviation of 2.5 billion dollars. There have also been 57 successful IPOs of SPACs that are currently searching for a target company, accumulative proceedings equal to 11.9 billion dollars. Average proceedings equal 208.9 million dollars, while median proceedings equal 200 million dollars. As of the beginning of December, 17 SPACs are in the process of merging with a target company, meaning that the target has been selected by the management team and confirmed by the shareholders of SPAC, but the merger has not been completed yet. Such remains also the biggest deal in the healthcare sector in 2021 with a total enterprise value of more than 32 billion dollars. Additional statistics about previously mentioned phases are presented in Figure 2.

Another sector that has seen rising numbers of SPACs is technology.

There have been 107 initial public offerings of SPACs that are looking for targets in the technology sector, which is 50 more than in the healthcare sector. Total proceedings of these IPOs equal 27.7 billion dollars compared to 11.9 billion dollars raised by the SPACs searching for targets in the healthcare sector. Average and median proceedings of IPO are also higher in the technology sector, 259 million and 230 million, respectively. The range of these proceedings is larger for the healthcare sector as is the standard deviation. Visual representation of the spread of SPAC IPO proceedings in the two sectors is provided in Figure 3A.

There have been 28 completed mergers (joint total enterprise value of 54.9 billion dollars) in the technology sector compared to 40 (joint total enterprise value of 70.1 billion dollars) in the healthcare sector. Completed mergers in the technology sector had higher average total enterprise value after the merger (1.96 billion dollars), higher median total enterprise value after the merger (1.22 billion dollars) and lower standard deviation (2.1 billion dollars). Visual representation of the spread of total enterprise values for completed mergers is presented in Figure 3B.
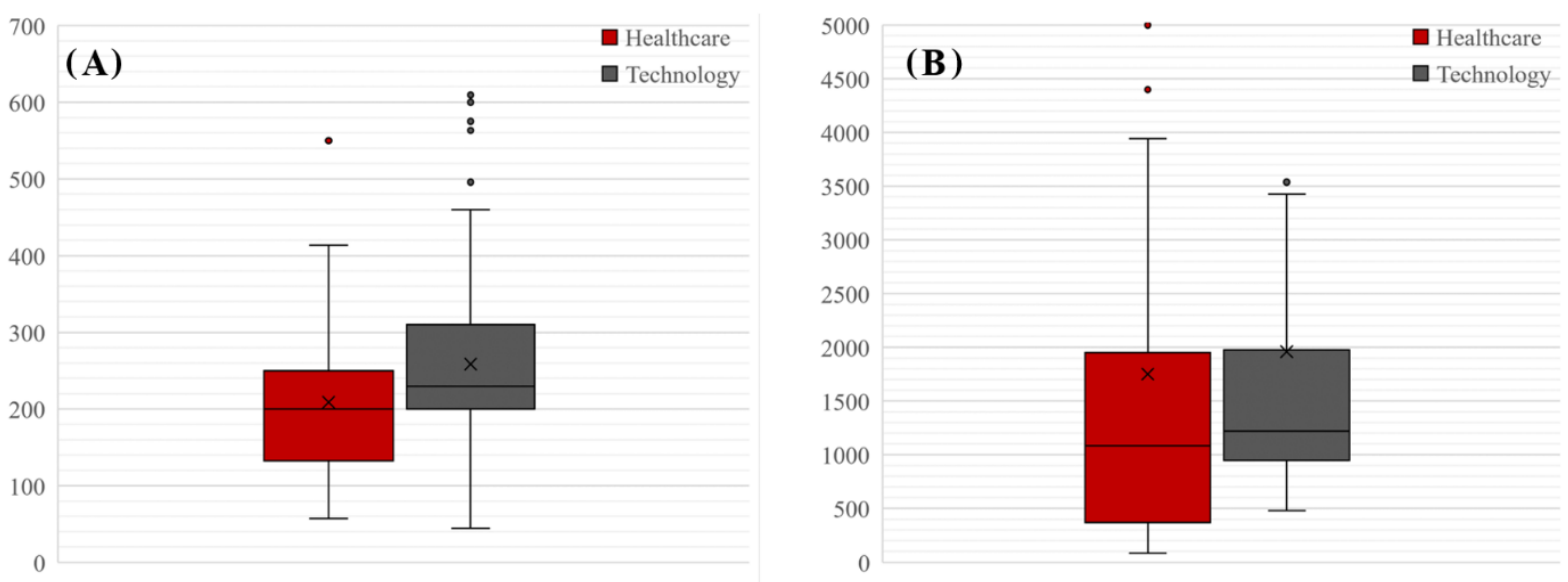

Figure 3. (A): Comparison of IPO proceedings of SPACs searching for a target in the selected sectors in 2021 (ordinate axis showing proceedings in M\$). One outlier for the healthcare sector is not shown on the boxplot. The authors' calculations are based on data available at the SPAC Insider Statistics database. B: Comparison of total enterprise values after the merger for the selected sectors in 2021 (ordinate axis showing total enterprise value in M\$). Two outliers for the technology sector and one outlier for the healthcare sector are not shown on the boxplot. The authors' calculations are based on data available at the SPAC Insider Statistics database.

\section{Conclusions}

SPACs have gained much popularity in the past two years, however, due to increased threats of regulatory actions, the excitement is decreasing (The Economist, 2021). Although the Securities and Exchange Commission (abbreviated SEC) did not take much interest in SPACs from the beginning, it changed its stance in July 2021 with a charge for misleading disclosures ahead of a merger (Securities and Exchange Commission, 2021). With this charge, SEC showed that it demands the same level of transparency and 
pre-transaction due diligence for SPACs as it does for traditional IPO deals and mergers (Brown Brothers Harriman, 2021). Similarly to American counterpart, European regulator European Securities and Markets Authority (ESMA) announced the requirement of adequate reviews of SPACs in addition to mandatory disclosure for retail investors with an explanation of potential risk factors, such as share dilution and funding structure (European Securities and Markets Authority, 2021). What the future holds for SPACs is uncertain, but if their growth continues, regulators will inevitably enforce stricter protocols of oversight.

Conflicts of Interest: The authors declare no conflict of interest.

\section{References}

1. Brown Brothers Harriman (2021), SPACs: Fad or future?. Accessed 17.12.2021. Available from: https://www.bbh.com/us/en/insights/blog/on-the-regs/spacs--fad-or-future-.html

2. European Securities and Markets Authority (2021), SPACs: prospectus disclosure and investor protection considerations. Accessed 22.12.2021. Available from: https://www.esma.europa.eu/sites/default/files/library/esma32-384-5209_esma_public_statement_spacs.pdf

3. Hale L. SPAC: A financing pool with something for everyone. J Corp Account Finance. 2006; 18(2): 67-74

4. $\quad$ DOI: $10.1002 /$ jcaf.20278

5. Heredia T, Fernandez-Galiano J, Garcia M. The SPACs boom. Deloitte insights. 2021. Available from: https://www2.deloitte.com/xe/en/insights/industry/financial-services/spacs-in-europe.html

6. Jenkinson T, Sousa M. Why SPAC investors should listen to the market. SSRN Electronic J. 2009. DOI: 10.2139/ssrn.1341771

7. Klausner M, Ohlrogge, M. A sober look at SPACs. SSRN Electronic J. 2020. DOI: 10.2139/ssrn.3720919

8. Securities and Exchange Commission (2021), SEC Charges SPAC, sponsor, merger target, and CEOs for misleading disclosure ahead of proposed business combination. Accessed 23.12.2021. Available from: https://www.sec.gov/news/press-release/2021-124

9. SPAC Insider (2021), SPAC IPO Transactions statistics. Accessed 28 November 2021. Available from: https://spacinsider.com/stats/

10. SPAC Research (2021), Special purpose acquisition company. Accessed 17.12.2021. Available from https://www.spacresearch.com/

11. The Economist (2021), Have SPACs been cleaned up?. Accessed 24.12.2021. Available from: https://www.economist.com/finance-and-economics/2021/12/04/have-spacs-been-cleaned-up

12. The Goldman Sachs Group, Inc. (2021), The IPO SPAC-tackle. Accessed 15.12.2021. Available from https://www.goldmansachs.com/insights/pages/top-of-mind/the-ipo-spac-tacle/report.pdf 